\title{
Menggali Nilai-Nilai Budaya dalam Peribahasa Etnis untuk Materi Pelajaran Muatan Lokal Bahasa dan Sastra Daerah
} dalam Pembentukan Wawasan Keindonesiaan:
Perspektif Antropolinguistik

\author{
Mardi Nugroho*) \\ Sarjana Sastra, Subbidang Pengkajian Bahasa, Pusat Bahasa
}

\begin{abstract}
Abstrak
Pada era reformasi ini, selain berbagai bencana dan persoalan-persoalan lain, bangsa Indonesia menghadapi ujianujian berat yang berkaitan dengan sentimen primordial. Ujianujian itu misalnya ada daerah yang ingin lepas dari NKRI, daerah yang ingin lepas dari induknya menjadi provinsi atau kabupaten baru, dan pemaksaan agar daerahnya dipimpin oleh figur-figur dari kelompok etniknya. Bisa dikatakan bahwa keindonesiaan yang terbentuk belum sepenuhnya utuh dan belum kokoh. Oleh karena itu, perlu diupayakan terbentuknya wawasan keindonesiaan pada segenap komponen NKRI yang diharapkan akan memperkokoh keindonesiaan kita.

Berbagai buku muatan lokal sudah memanfaatkan hasil penelitian tentang peribahasa dalam suatu etnik, misalnya buku Peribahasa Gorontalo: Rujukan Mata Pelajaran Muatan Lokal karya Mansur Pateda dengan Yennie P. Pulubuhu, namun belum menganalisis aspek kebudayaannya. Ada penelitian ungkapan dalam etnik lain, misalnya penelitian Fatimah Djajasudarma dkk. berjudul Nilai Budaya dalam Ungkapan dan Peribahasa Sunda. Namun, penelitian-penelitian seperti itu masih terlalu sedikit. Memang, kajian antropolinguistik (etnolinguistik atau antropologi linguistik) belum populer dan belum banyak berkembang di Indonesia, padahal Indonesia adalah "surga" bagi kajian antropolinguistik dengan beratus-ratus etnik di dalamnya.

Dalam salah satu subtema seminar "Muatan Lokal Bahasa

dan Sastra Daerah dalam Pembentukan Wawasan Keindonesiaan", makalah ini menyarankan untuk menggali nilainilai budaya dalam peribahasa etnik-etnik yang ada di Indonesia dalam perspektif antropolinguistik. Selain itu, juga akan dipaparkan metode yang dapat digunakan dan beberapa contoh kajian yang telah dilakukan mengenai peribahasa etnis yang dapat dimanfaatkan untuk tema ini.

Bagi peserta didik, peribahasa dalam etniknya sendiri maupun dalam etnik-etnik lain di sekitarnya sangat relevan diajarkan dalam pelajaran muatan lokal bahasa dan sastra daerah. Dari peribahasa yang ada itu digali nilai-nilai budayanya, dipilih mana yang dapat diunakan untuk
\end{abstract}


membangun wawasan keindonesiaan, mana yang perlu diterengjelasakan dan diambil langkah antisipasi agar tidak mendorong konflik, seperti terhadap ungkapan dalam bahasa Madura 'Atembheng poteh tolang bi' poteh mata, anggo'a poteya telang" "Daripada putih tulang dan putih mata lebih baik putih tulang', karena ungkapan itu disinyalir dapat memicu konflik.

\section{Pengantar}

Pada era reformasi ini, selain berbagai bencana dan persoalanpersoalan lain, bangsa Indonesia menghadapi ujian-ujian berat yang berkaitan dengan sentimen primordial. Ujian-ujian itu misalnya ada daerah yang ingin lepas dari NKRI, daerah yang ingin lepas dari induknya menjadi provinsi atau kabupaten baru, dan pemaksaan agar daerahnya dipimpin oleh figur-figur dari kelompok etniknya. Bisa dikatakan bahwa keindonesiaan yang terbentuk belum sepenuhnya utuh dan belum kokoh. Oleh karena itu, perlu diupayakan terbentuknya wawasan keindonesiaan pada segenap komponen NKRI yang diharapkan akan memperkokoh keindonesiaan kita.

Berbagai buku muatan lokal sudah memanfaatkan hasil penelitian tentang peribahasa dalam suatu etnik, misalnya buku Peribahasa Gorontalo: Rujukan Mata Pelajaran Muatan Lokal karya Mansur Pateda dengan Yennie P. Pulubuhu, namun belum menganalisis aspek kebudayaannya. Ada penelitian ungkapan dalam etnik lain, misalnya penelitian Fatimah Djajasudarma dkk. berjudul Nilai Budaya dalam Ungkapan dan Peribahasa Sunda. Namun, penelitian-penelitian seperti itu masih terlalu sedikit. Memang, kajian antropolinguistik belum populer dan belum banyak berkembang di Indonesia, padahal Indonesia adalah "surga" bagi kajian antropolinguistik. Saya katakan surga mengingat Indonesia terdiri atas beratus-ratus etnik dengan bahasa yang beratus-ratus juga, sehingga Indonesia merupakan tambang yang 
berlimpah-limpah untuk digali oleh peneliti antropolinguistik yang senang berdarma bagi negara. Atau, sekedar sebagai objek penelitian untuk menambah angka kredit dan menambah penghasilan.

Dalam salah satu subtema seminar "Muatan Lokal Bahasa dan Sastra Daerah dalam Pembentukan Wawasan Keindonesiaan”, makalah ini menyarankan untuk menggali nilai-nilai budaya dalam peribahasa etnik-etnik yang ada di Indonesia dalam perspektif antropolinguistik.

\section{Pembahasan}

\subsection{Antropolinguistik}

Antropolinguistik merupakan interdisiplin antara linguistik (ilmu bahasa) dengan antropologi. Ada yang menamakannya etnolinguistik, linguistik budaya, antropologi linguistik, atau linguistik antropologi yang secara umum memiliki kesamaan (Ahimsa-Putra dalam Widyaparwa: Majalah Ilmiah Bahasa dan Sastra. Oktober 1997; Crystal, 1992; Duranti, 2000).

Munculnya antropolinguistik tidak dapat dipisahkan dari Franz Boas. Franz Boas telah menumbuhkan tradisi dan minat, yakni penelitian lapangan yang seksama mengenai sejarah berbagai macam suku bangsa atau etnik Indian serta bahasa-bahasa mereka yang kemudian dikembangkan oleh beberapa orang muridnya, antara lain Edward Sapir. Sapir inilah yang merupakan salah satu perintis studi antropolinguistik, karena dia yang mulai membuka sebuah persoalan baru yang penting dalam antropoliguistik, yakni hubungan antara bahasa dan kebudayaan. Beberapa pandangan Sapir kemudian dikembangkan lebih lanjut oleh salah seorang muridnya, Benjamin Lee Whorf. 
Sapir mengatakan bahwa dalam bahasa tercermin pengetahuan masyarakat pemilik bahasa tersebut mengenai lingkungannya, sehingga lingkungan yang sama tidak dilihat secara sama oleh tiap-tiap etnik atau masyarakat yang memiliki bahasa yang berbeda. Pandangan Sapir ini, terutama mengenai bahasa dan persepsi manusia kemudian dikembangkan oleh Benjamin Lee Whorf. Whorf, antara lain, berpendapat bahwa cara orang memandang, memahami, serta menjelaskan berbagai macam gejala atau peristiwa yang dihadapinya sangat dipengaruhi oleh bahasa yang digunakannya. Bahasa yang digunakan oleh suatu masyarakat, tanpa disadari, memengaruhi cara masyarakat itu dalam memandang lingkungannya. Pendapat Sapir dan Whorf ini kemudian terkenal sebagai "hipotesis Sapir-Whorf".

\subsection{Menggali Nilai-Nilai Budaya dalam Peribahasa Etnis untuk Materi Pelajaran Muatan Lokal Bahasa dan Sastra Daerah dalam Pembentukan Wawasan Keindonesiaan: Perspektif Antropolinguistik}

Seperti dikatakan oleh Sumarsono (dalam Linguistik Indonesia, Juni dan Desember 1997) tujuan utama pengajaran bahasa daerah adalah melestarikan bahasa dan budaya masyarakat tutur bahasa daerah bersangkutan. Implikasinya antara lain, silabus pengajaran bahasa daerah harus dalam ranah-ranah penggunaan yang lebih ke wilayah "budaya" daerah.

Di atas telah dikatakan bahwa dalam bahasa tercermain pengetahuan masyarakat pemilik bahasa bersangkutan mengenai lingkungannya. Dengan kata lain, pengetahuan masyarakat pemilik bahasa tercermin dalam bahasanya, yaitu tercermin dalam wujud kata- 
kata, kalimat-kalimat, peribahasa, wacana, dalil-dalil, bahkan dalam teori-teori.

Peribahasa merupakan kalimat yang susunannya tetap dan kalimat yang susunannya tetap itu dipakai berulang-ulang, sehingga diharapkan persepsi yang tercermin atau terkodekan dalam kalimat itu akan tertanam kuat dalam pikiran murid. Hal itu karena bahasa, termasuk peribahasa, dapat mengarahkan persepsi pemakainya, semakin diulang-ulang maka semakin kuat tertanam dalam pikiran (Thomas, Linda dan Shan Wareing. 2007).

Perlu ditegaskan bahwa bidal, ungkapan, dan perumpamaan termasuk ke dalam peribahasa, karena pengertian peribahasa (dalam Kamus Besar Bahasa Indonesia, 2005) adalah:

1. Kelompok kata atau kalimat yang tetap susunannya, biasanya mengiaskan maksud tertentu (dalam peribahasa termasuk juga bidal, ungkapan, perumpamaan); 2. Ungkapan atau kalimat ringkas padat, berisi perbandingan, perumpamaan, nasihat, prinsip hidup atau aturan tingkah laku.

Pepatah dan petatah-petitih juga termasuk termasuk dalam peribahasa, karena pengertian pepatah (dalam Kamus Besar Bahasa Indonesia, 2005) adalah:

peribahasa yang mengandung nasihat atau ajaran dari orang tuatua (biasanya dipakai atau diucapkan untuk mematahkan lawan bicara), seperti tong kosong nyaring bunyinya 'orang yg tidak berilmu banyak bualnya'

Sementara itu, pengertian pepatah-petitih (dalam Kamus Besar Bahasa Indonesia, 2005) adalah 'berbagai peribahasa'.

Nilai adalah sebuah konsepsi, eksplisit atau implisit, yang khas milik seseorang individu atau suatu kelompok tentang yang seharusnya 
diinginkan yang memengaruhi pilihan yang tersedia dari bentuk-bentuk, cara-cara, dan tujuan-tujuan tindakan (Kluckhohn dalam Marzali, 2007). Selanjutnya, Marzali menjelaskan bahwa kita harus memerhatikan kalimat kuncinya, yaitu "nilai" adalah "konsepsi tentang hal yang seharusnya diinginkan". Di sini perlu diingatkan bahwa "hal yang seharusnya diinginkan" adalah berbeda dari "hal yang diinginkan". Kedua hal itu jangan dikelirukan.

Sebagai konsepsi, nilai adalah abstrak, sesuatu yang dibangun dan berada di dalam pikiran atau budi, tidak dapat diraba dan dilihat secara langsung dengan pancaindra. Nilai hanya dapat disimpulkan dan ditafsirkan dari ucapan, perbuatan, dan materi yang dibuat manusia. Ucapan, perbuatan, dan materi adalah manifestasi dari nilai. Untuk memeroleh nilai yang terkandung dalam suatu ucapan atau suatu perbuatan, seseorang harus melakukan penafsiran dan penarikan kesimpulan.

Metodologi yang dapat digunakan dalam penelitian ini (diambil dari buku Prof. Robert Sibarani. 2004. Atropolinguistik: Antropologi Linguistik, Linguistik Antropologi) sebagai berikut. Metode pengumpulan data yang dapat digunakan adalah metode wawancara mendalam, metode observasi, baik observasi-partisipatif maupun observasi periodik ke lapangan, dan metode kajian tertulis. Pendekatan kualitatif akan lebih bermakna dalam penelitian ini dengan menerapkan teknik elisitasi untuk mendapatkan data sebanyak-banyaknya dari berbagai sumber (Padanan untuk kata elisitasi ini menurut Kridalaksana adalah pemuntiran data atau pamancing). Analisis data untuk mendapatkan ketuntasan informasi dapat dilakukan dengan teknik triangulasi, baik triangulasi metode, triangulasi sumber data, triangulasi teori, maupun triangulasi 
penganalisis. Analisis dalam penelitian ini juga dapat memanfaatkan kajian-kajian linguistik, kajian antropologi, dan kajian semiotik.

\subsection{Beberapa contoh hasil kajian mengenai peribahasa etnis yang dapat dimanfaatkan untuk subtema seminar ini}

\subsubsection{Berfikir Positif Orang Flores (Inyo Yos Fernandes)}

Masyarakat Lamaholot, Flores memiliki keenderungan mudah beradaptasi dengan kelompok etnik yang lain. Bahkan Raja Larantuka, sebagai keturunan Pusi-Goa, putra Patigolo Arakian sebagai penguasa kelompok masyarakat Lamaholot berasal dari etnik lain (Sina Jawa), seperti terungkap dalam bahasa Lamaholot sebagai berikut.

Kropon lodo tobo ia

Tobo deo apa utan

Tobo deo apa utan

Tobo nupa lake wae
'Hai pemuda turun duduklah di sini Duduk berdekatan dengan manusia rimba

Duduk berdampingan dengan manusia rimba

Hidup berdampingan bagaikan suami istri'

Ungkapan di atas menunjukkan keterbukaan dan penerimaan orang asli pribumi Lamaholot (dalam teks di atas disebut sebagai apa utan 'manusia rimba') terhadap kaum pendatang. Kaum pendatang tidak hanya diberi tanah tetapi juga kekuasaan yang istimewa dalam struktur kekuasaan tradisional mereka. Sikap seperti ini pun menjadi dasar bagi keberanian orang pribumi Lamaholot untuk tidak enggan menjadi perantau di negeri orang.

Pana mai Sina Jawa 'Pergilah merantau ke tanah asalmu Sina Jawa 
pana maan mae-mae

gawe maan sare-sare. melangkah ke tanah leluhur dengan hati teguh

menapaki jejak leluhur dengan mantap langkah.'

Tanah rantau sering identik dengan istilah "Sina Jawa", yang dalam keyakinan pandangan orang Lamaholot dianggap sebagai tanah asal leluhur mereka. Pergi merantau bagi orang Lamaholot sama dengan menapaki jejak para leluhur (napak tilas) ke tanah asal mereka.

\subsubsection{Berpikir Positif dalam Budaya Minang (Magdalia}

\section{Alfian)}

Dalam menjalin kerjasama dalam masyarakat Minang, pepatah mengajarkan:

Barek samo dipikue

ringan samo dijinjiang.

Ado samo dimakan

indak samo dicari.
'Berat sama dipikul ringan sama dijinjing. Yang ada sama dimakan yang tiada sama dicari.'

Dalam menghadapi suatu persoalan tentulah ada perbedaan pendapat/pandangan, bak kata pepatah: "Kepala sama hitam, pendapat berbedaa-beda". Perbedaan pendapat adalah sangat lumrah bagi orang Minang. Kalau dibiarkan berlanjut pastilah akan berakibat buruk. Oleh karena itu, harus dicari jalan keluarnya. Jalan keluarnya adalah dengan melakukan musyawarah untuk mufakat. Pepatah minang menggambarkan proses pengambilan keputusan sebagai berikut.

Bulek aie dek pambuluh

bulek kato dek mupakaik.

Bulek nak buliah digolongkan
'Bulat air karena pembuluh bulat kata karena mufakat.

Bulat supaya boleh digelindingkan 
...Pembentukan Wawasan Keindonesiaan: Perspektif Antropolinguistik

picak nak buliah dilayangkan gepeng supaya boleh dilayangkan.'

Setelah diambil keputusan, semua harus menyetujui dan menjalankannya.

Dalam kehidupan sehari-hari, terdapat empat landasan berpikir orang Minang menurut adat, yaitu:

1. logika yang disebut dengan alue patuik

2. tertib hokum yang disebut anggo tanggo

3. ijtihad/penelitian yang disebut raso pareso

4. musyawarah atau mufakat

Raso pareso artinya rasa dan periksa atau teliti. Orang minang dituntut membiasakan diri untuk mempertajam rasa kemanusiaan atau hati nurani yang luhur dalam kehidupan sehari-hari. Dalam menghadapi setiap masalah, kita dituntut membiasakan diri melakukan penelitian yang cermat untuk mendapatkan kebenaran hakiki dan tidak tergesa-gesa dalam bertindak, seperti tercermin dalam pepatah berikut ini.

Nan kuriak iyolah kundi

nan merah iyolah sago

Nan baiak iyolah budi

nan indah iyolah baso.
'Yang burik iyalah kundi

yang merah ialah saga

Yang baik ialah budi

yang indah ialah basa (basi).'

Perbedaan antara raso dan pareso disebut dalam pepatah sebagai berikut.

Raso tumbuah di dado

pareso tumbuah di kapalo
Rasa tumbuh di dada periksa tumbuh di kepala (otak)

Adat Minang mengutamakan sopan santun dalam pergaulan. Budi pekerti yang tinggi menjadi salah satu ukuran martabat seseorang. Etika menjadi salah satu sifat yang harus dimiliki oleh setiap individu. 


\subsubsection{Kearifan dari sastra lisan Madura (D. Zawawi Imron)}

\section{a. Pandangan hidup}

Pandangan hidup orang Madura banyak yang tertuang dalam ungkapan, seloka, pantun, lagu, dan lain-lain. Pada pokoknya pandangan hidup orang Madura dibagi menjadi dua:

a. Pandangan hidup keduniawian ada seloka berbunyi:

Abantal ombak 'asepo 'angen

'Berbantal ombak berselimut angin'.

Menggambarkan sikap hidup dinamis dan energik dan tabah untuk menghadapi berbagai tantangan dan cobaan. Hidup harus dihadapi dengan kerja keras.

b. Pandangan keagamaan (religi) ada seloka berbunyi:

Abantal syahadat asapo' iman

'Berbantal syahadat berselimut iman'.

Seloka tersebut menggambarkan bahwa orang Madura itu harus menyerah penuh kepada ajaran Allah atau ajaran agama.

\section{b. Tatakrama (Adat Istiadat)}

Dalam pandangan hidup orang Madura, tatakrama (budi pekerti) harus diutamakan. Tentang pentingnya budi pekerti itu tersirat pada ungkapan:

Oreng andhi' tatakrama 'Orang yang punya budi pekerti yang baik itu

reya akantha pesses seperti uang (emas)

Singgapur, ekabalja Singapura, dibelanjakan

an'a e dhimma bai paju. di mana saja pasti laku.'

Adagium itu menggambarkan pentingnya budi pekerti. Juga tersirat, dengan bekal budi pekerti yang baik, orang pergi ke mana saja akan 
disenangi (diterima) orang. Akan tetapi, orang yang tidak berbudi pekerti disebut:

Ta'tao Judanegara ITidak mengenal Judanegara'.

Dalam tatakrama ada andhap asor, rendah hati dan tidak sombong. Judanegara adalah seorang tumenggung di Madura yang sangat baik budi pekertinya, sehingga pantas dijadikan kaca kebbang (contoh teladan) bagi orang Madura. Orang yang disebut tidak mengenal (ajaran) Judanegara dianggap jauh dari sikap mulia, alias hina.

\section{c. Persahabatan}

Ada seloka berbunyi:

Bila cempa palotan

bila kanca taretan.
'Setiap beras cempa itu ketan, setiap teman itu saudara.'

Ungkapan itu melukiskan bahwa teman atau sahabat harus diperlakukan sebagai saudara sendiri.

\subsubsection{Berpkir Positif dalam Masyarakat Batak Toba (Robert Sibarani)}

Pada masyarakat Batak Toba ada perumpamaan yang berbunyi, "mata guru roba sisean", yang berarti 'mata menjadi guru yang mengajar, pikiran menjadi murid yang diajari'. Perumpamaan ini memberikan makna kepada kita bahwa kita jangan hanya bersandar kepada pikiran kita atau kepada kehendak kita, tetapi harus lebih dahulu kepada kenyataan empirik yang dapat ditangkap oleh mata. Kenyataan yang dapat ditangkap oleh mata (pancaindra) pasti lebih benar daripada kehendak pikiran kita. Pikiran yang merupakan wujud kehendak harus diarahkan oleh mata yang merupakan wujud kenyataan. Makna perumpamaan ini sama dengan konsep induktif-empiris dalam dunia ilmiah sekarang ini. 
Akan tetaapi, perlu ada keseimbangan antara mata sebagai salah satu alat pengindra kebenaran yang jelas terlihat dengan pikiran yang bisa menilai kebenaran di tengah-tengah kehidupan masyarakat. Itulah yang dinyatakan dalam perumpamaan berikut.

Nidanggurbon jarum

tu na potpot

dang diida mata,

alai diboto roba.
'Dilemparkan jarum ke rumput yang lebat tidak dilihat mata, tetapi diketahui pikiran.'

Perumpamaan itu bermakna bahwa banyak hal dalam kehidupan manusia yang tidak dapat dilihat mata, tetapi dapat dirasakan bahkan ditangkap pikiran seperti jarum yang dilemparkan ke rerumputan yang lebat, tidak terlihat oleh mata, tetapi dapat ditebak oleh pikiran atau perasaan di mana letaknya. Banyak hal yang tidak perlu ditanyakan, yang tidak perlu diselidiki lagi atau yang tidak perlu diperlihatkan, tetapi sudah diketahui oleh pikiran dan perasaan karena kalau ditanya atau diperlihatkan akan menimbulkan sakit hati kepada orang lain. Inilah juga yang disebut dengan konsep deduktif-rasional dalam dunia keilmuan sekarang ini.

Dalam dua perumpamaan di atas terlihat bahwa perlu ada kehatihatian supaya jangan menimbulkan rasa sakit hati atau perselisihan, tetapi sebaliknya dapat memberikan kedamaian di tengah-tengah masyarakat. Jika ada kekurangan dalam perilaku dan perbuatan sesama teman, tidak perlu diperlihatkan kepada orang lain supaya hal itu jangan memermalukan atau menyinggung perasaan. Sebaiknya, kedamaian dan kebaikanlah yang diperbuat kepada sesama teman dan jangan mencaricari kekurangan orang lain. Hal itu juga dengan jelas diwariskan oleh nenek moyang kita dalam perumpamaan yang berkata: 
...Pembentukan Wawasan Keindonesiaan: Perspektif Antropolinguistik

si Deak;

ia i na ummuli, i ma

tapareak. si Deak

mana yang lebih baik, itulah kita lakukan.'

Perumpamaan itu bermakna bahwa lakukanlah yang baik kepada sesama manusia. Kalau ada kesalahan atau kekurangan orang, sepatutnya diperbaiki seperti kata perumpamaan:

$\begin{array}{ll}\text { Pauk-pauk budali, } & \text { Lambaian pacul, } \\ \text { pago-pago tarugi; } & \text { pancang lidi; } \\ \text { na tading niulabi, } & \text { yang tertinggal diulangi, } \\ \text { na sega pinauli. } & \text { yang rusak diperbaiki.' }\end{array}$

yang berarti bahwa yang belum selesai diselesaikan dan yang rusak diperbaiki.

Kesalahan atau kekurangan teman tidak baik dibukakan atau diungkit-ungkit karena dapat menimbulkan perselisihan dan rasa sakit hati seperti apa yang dinyatakan dalam perumpamaan:

Jujur jumadi bada, 'Menghitung-hitung awal pertengkaran,

bolus jumadi badameon. melalui awal kedamaian.'

yang berarti bahwa jika mengungkit-ungkit kesalahan orang, itulah awal perselisihan, sebaliknya jika kita melupakan kesalahan orang, itulah awal kedamaian. Hal itu juga sesuai dengan perumpamaan:

Manat unang tartuktuk,

nenget unang tarrobung
'Hati-hati

tersandung,

perlahan-lahan

terjerumus.' jangan jangan

Yang berarti bahwa kita harus berhati-hati supaya tidak tersandung dalam segala pekerjaan. 
Pada waktu berbicara pun kita harus berhati-hati seperti kata perumpamaan:

\section{Jolo nidilat bibir}

asa nidok bata.

$$
\begin{aligned}
& \text { 'Lebih dahulu dijilat bibir } \\
& \text { baru diucapkan perkataan.' }
\end{aligned}
$$

yang berarti 'pikir dahulu baik-baik, baru diucapkan'. Setiap ucapan harus kita pikirkan apakah menimbulkan ketersingungan atau kesenangan kepada orang lain. Itulah sebabnya ada perumpamaan:

Na niida ni mata, 'Yang terlihat oleh mata, pinaula so niida; pura-pura tidak dilihat; na binege ni pinggol yang terdengar oleh telinga pinaula so binege.

yang berarti bahwa, dalam beberapa hal 'yang dilihat mata pura-pura tidak kita lihat, yang didengar telinga, pura-pura tidak kita dengar' jika hal itu menimbulkan ketersinggungan atau perselisihan.

Dalam kehidupan sehari-hari, kita harus pintar dalam pengetahuan dan bijak dalam perasaan supaya tercapai kedamaian. Perumpamaan kita berkata:

Marroba songon ulok, 'Berpikir seperti ular, marbisuk songon darapati bijaksana seperti merpati' yang bermakna agar kita mempergunakan pikiran dan pengetahuan (kecerdasan intelektual) dan kebijaksanaan dan perasaan (kecerdasan emosional) dalam mempertimbangkan pembicaraan, perselisihan, atau permasalahan lain. 


\subsubsection{Ungkapan Tradisional sebagai Sumber Informasi Kebudayaan Daerah Sumatera Selatan (M.Sapawi dkk)}

\section{a. Ungkapan untuk Persatuan dan Kesatuan}

\section{Sebiduk lain panggo}

Sebiduk lain duduk, tempat duduk dalam perahu

Terjemahan bebas: Sebiduk lain tempat duduk

\section{Uraian:}

Bilamana kita berperahu, maka ke mana pun perahu ini melaju akan bersama-sama menuju suatu arah. Tetapi dalam ungkapan ini dikatakan bahwa kita satu perahu tetapi mempunyai kehendak dan tujuan yang berbeda, seolah-olah tidak sehaluan, serta tidak dalam keadaan perahu yang sama. Jadi satu perahu tapi masing-masing ingin mengarahkan perahunya masing-masing. Jelas ini tidak menemukan titik pertemuan sebab mempunyai keinginan yang berbeda. Sebagai contoh dapat diibaratkan sebagai berikut: Umpamanya suatu keluarga sedang menghadapi masalah, dalam hal ini satu sama lain mempunyai keinginan atau kehendak yang berbeda-beda. Jadi dalam hal ini keluarga tersebut tidak pernah sehaluan dalam setiap pendapat.

Ungkapan ini bermaksud menasihati atau menyindir terhadap suatu keluarga yang tidak pernah kompak, ada-ada saja yang menjadi bahan pertengkaran di antara mereka. Sehingga masalah kecil pun menjadi perdebatan. Jadi ungkapan ini bermaksud mengingatkan atau menyadarkan agar orang menyadari betapa pentingnya rasa kesatuan dan persatuan itu, jadi janganlah hal-hal yang kecil saja menjadi persoalan. 


\section{b. Ungkapan Agar Tidak Mementingkan Diri Sendiri}

\section{Terbang burung beinsang ikan.}

Terbang burung berinsang ikan.

Terjemahan bebas: 'Terbang burung berinsang ikan.'

\section{Uraian:}

Ungkapan ini menggambarkan tindakan seseorang yang tidak memedulikan siapa pun. Pokoknya yang penting bagi diri sindiri adalah mendapat untung yang sebesar-besarnya. Sebagai misal adalah seseorang yang mencari nafkah, untuk mendapat keuntungan tidak menghiraukan siapa pun. Umpamanya seseorang yang berdagang, dalam menjual barang dagangannya dia tidak menghiraukan siapa pun, pokoknya dia mendapat untung dari hasil penjualan tersebut. Jadi walaupun dengan saudara ataupun orang yang memberi dia modal, tetap dia akan mengambil untung sebagaimana dia menjual barangnya kepada orang lain.

\section{Penutup}

Dari beberapa contoh di atas kiranya jelas kelihatan bahwa peribahasa-peribahasa itu dapat kita kemas untuk materi pelajaran muatan lokal yang dapat membangun wawasan keindonesiaan. Penulis yakin, masih banyak sekali yang masih terpendam yang menunggu untuk kita teliti.

Selain mengambil peribahasa dari etnik yang ada di daerah bersangkutan, pada hemat penulis, kita juga dapat mengalihkonsepkan peribahasa dari suatu etnik ke etnik yang lain atau ke dalam bahasa Indonesia dan sebaliknya. Sementara itu, terhadap peribahasa yang berpotensi mengganggu keindonesian kita, perlu diterengjelasakan dan diambil langkah antisipasi agar tidak mendorong konflik, seperti terhadap 
...Pembentukan Wawasan Keindonesiaan: Perspektif Antropolinguistik

ungkapan dalam bahasa Madura "Atembheng poteh tolang bi' poteh mata, anggo'a poteya telang" 'Daripada putih tulang dan putih mata lebih baik putih tulang', karena ungkapan itu disinyalir dapat memicu konflik (Adianto dalam Jurnal ATL No. 8 Vol 7, Desember 2002). Contoh yang lain peribahasa dalam bahasa Jawa mangan ora mangan nek ngumpul 'makan tidak akan asal kumpul' yang disinyalir dapat menghambat program transmigrasi (Kontjaraningrat, 1984). 


\section{Daftar Pustaka}

Adianto, M. Rus. "Memahami Potensi Konflik dan Perdamaian dalam Budaya Dayak dan Madura Melalui Bahan-Bahan Tradisional" dalam Jurnal ATL No. 8 Vol 7, Desember 2002.

Ahimsa-Putra, H. Shri. "Etnolinguistik: Beberapa Bentuk Kajian” dalam Widyaparwa: Majalah Ilmiah Bahasa dan Sastra. Oktober 1997.

Alfian, Magdalia. "Berpikir Positif dlm Budaya Minang" dalam PaEni, Mukhlis dan Pudentia MPSS. 2005. Bunga Rampai Budaya Berfikir Positif Suku-Suku Bangsa. Jakarta: Departemen Kebudayaan dan Pariwisata bekerja sama dengan Asosiasi Tradisi Lisan (ATL).

Crystal, David. 1992. A Dictionary of Linguistics and Phonetics. New York: Blackwell Publishers.

Duranti, Alessandro. 2000. Linguistic Anthropology. Cambridge: Cambridge University Press.

Fernandes, Inyo Yos "Berfikir Positif Orang Flores" dalam PaEni, Mukhlis dan Pudentia MPSS. 2005. Bunga Rampai Budaya Berfikir Positif Suku-Suku Bangsa. Jakarta: Departemen Kebudayaan dan Pariwisata bekerja sama dengan Asosiasi Tradisi Lisan (ATL)).

Imron, D. Zawawi. "Kearifan dari sastra lisan madura" dalam PaEni, Mukhlis dan Pudentia MPSS. 2005. Bunga Rampai Budaya Berfikir Positif Suku-Suku Bangsa. Jakarta: Departemen Kebudayaan dan Pariwisata bekerja sama dengan Asosiasi Tradisi Lisan (ATL).

Kontjaraningrat. 1984. Kebudayaan Jawa. Jakarta: Balai Pustaka. . 1990 Pengantar Ilmu Antropologi. Jakarta: Rineka Cipta.

Kridalaksana, Harimurti. 2008. Kamus Linguistik. Jakarta: Graedia Pustaka Utama.

Mahsun. "Bahasa Daerah sebagai Sarana Peningkatan Pemahaman Kondisi Kebinekaan dalam Ketunggalikaan Masyarakat 
Indonesia: ke Arah Pemikiran dalam Mereposisi Fungsi Bahasa Daerah" dalam Alwi, Hasan dan Dendy Sugono (Ed.). 2000. Politik Bahasa: Risalah Seminar Plitik Bahasa. Jakarta: Pusat Bahasa.

Marzali, Amri. 2007. Antropologi dan Pembangunan Indonesia. Jakarta: Kencana Prenada Group.

Moleong, Lexi J. 1990. Metodologi Penelitian Kualitatif. Bandung: Remaja Rosdakarya.

Oktavianus. "Nilai Budaya dalam Ungkapan Minangkabau: Sebuah Kajian dari Perspektif Antropolinguistik" dalam Linguistik Indonesia: Jurnal Ilmiah Masyarakat Linguistik Indonesia. Februari 2006.

Sapawi, M. dkk. 1984. Ungkapan Tradisional sebagai Sumber Informasi Kebudayaan Daerah Sumatera Selatan. Jakarta: Proyek Inventarisasi dan Dokumentasi Kebudayaan Daerah, Departemen Pendidikan dan Kebudayaan.

Sibarani, Robert. 2004. Antropolinguistik: Antropologi Linguistik, Linguistik Antropologi. Medan: Poda.

"Berfikir Positif dalam Masyarakat Batak Toba" dalam PaEni, Mukhlis dan Pudentia MPSS. 2005. Bunga Rampai Budaya Berfikir Positif Suku-Suku Bangsa. Jakarta: Departemen Kebudayaan dan Pariwisata bekerja sama dengan Asosiasi Tradisi Lisan (ATL).

Sumarsono. "Bahasa Daerah sebagai Muatan Lokal: Ihwal Materi dan Metode" dalam Linguistik Indonesia: Jurnal Ilmiah Masyarakat Linguistik Indonesia. Juni dan Desember 1997.

Sutarto, Ayu. 2004. Menjinakkan Globalisasi: tentang Peran Strategis Produk-Produk Budaya Lokal. Jember: Kelompok Peduli Budaya dan Wisata Daerah Jawa Timur (Kompyawisda).

Thomas, Linda dan Shan Wareing. 2007. Bahasa, Masyarakat, dan Kekuasaan. Yogyakarta: Pustaka Pelajar.

Tim Penyusun Kamus Pusat Bahasa. 2005. Kamus Besar Bahasa Indonesia. Jakarta: Balai Pustaka. 